\title{
A utilização da contabilidade gerencial: um estudo em micro e pequenas empresas
}

\author{
Anderson Catapan* \\ Ana Carolina Teixeira Cortes ${ }^{* *}$ \\ Patrícia Baptista de Souza** \\ Rosângela Moreira dos Santos ${ }^{* * * *}$ \\ Vanessa Ventura da Silva ${ }^{* * * *}$
}

RESUMO - O objetivo deste trabalho é analisar a importância da contabilidade gerencial dentro das micro e pequenas empresas. Buscou-se verificar quais benefícios um profissional contábil trás para a organização, mostrando como ferramentas gerenciais podem auxiliar o gestor nas tomadas de decisões, identificação de problemas, planejamento e desenvolvimento de ações. Como resultado, verificou-se que parte das micro e pequenas empresas ainda não utilizam a função gerencial do contador, fornecedor de informações para a tomada de decisões.

Palavras-chave: Contabilidade gerencial. Micro e pequenas empresas. Ferramentas gerenciais.

\section{INTRODUÇÃO}

A contabilidade gerencial, segundo Hansen e Mowen (1997), é a parte do sistema contábil que se dedica às informações para os usuários internos da organização, ou seja, ao processo de coletar, identificar e fornecer informações importantes para dar apoio às necessidades dos gestores no planejamento, controle e processo decisório.

Cabe aos gestores utilizarem as informações fornecidas pela contabilidade gerencial para melhorar resultados e desempenho, prevenindo assim a mortalidade dessas empresas que estão em desenvolvimento e são de extrema importância para a economia do país. Segundo Arruda (2002), os obstáculos ou dificuldades encontrados pelas micro e pequenas empresas são em função do padrão de comportamento dos empresários em relação à competitividade que, * Doutorando em Administração na Pontifícia Universidade Católica-PR e Mestre em Contabilidade e Finanças pela Universidade Federal do Paraná. É professor do Departamento de Contabilidade da Pontifícia Universidade Católica-PR e Sócio-Diretor da Catapan Contadores Associados. Endereço eletrônico: anderson.catapan@pucpr. br.

** Graduanda em Ciências Contábeis na Pontifícia Universidade Católica-PR. Endereço eletrônico: ana.ctc@ gmail.com.

*** Graduanda em Ciências Contábeis na Pontifícia Universidade Católica-PR. Endereço eletrônico: patriciabs@, jmalucelli.com.br.

**** Graduanda em Ciências Contábeis na Pontifícia Universidade Católica-PR. Endereço eletrônico: rosangelamoreira.3184@gmail.com.

***** Graduanda em Ciências Contábeis na Pontifícia Universidade Católica-PR. Endereço eletrônico: vanessa. silva@remac.com.br. 
por sua vez, resulta da educação que tiveram e do ambiente em que vivem.

Neste sentido, segundo o SEBRAE (2011), o índice de mortalidade das micro e pequenas empresas diminuíu de 78\%, ao final do segundo ano, para $71 \%$, o que se deve, entre outros, ao planejamento nas empresas, que passou a ser preocupação. Dentro deste contexto, a questão de pesquisa deste artigo é: Qual a aderência das micro e pequenas empresas às ferramentas de contabilidade gerencial?

O artigo está estruturado em cinco partes, incluindo-se esta introdução. A segunda parte traz o referencial teórico que fundamenta o tema de pesquisa. Na sequência, apresentase a terceira parte que aborda os aspectos metodológicos da pesquisa de campo, seguidos da análise de dados e considerações finais desta pesquisa.

\section{REFERENCIAL TEÓRICO}

Este item aborda a fundamentação teórica da pesquisa, ilustrando conceitos inerentes à contabilidade gerencial e às micro e pequenas empresas.

\subsection{CONTABILIDADE GERENCIAL}

Para Marion (1982) a contabilidade gerencial é um grande instrumento que auxilia a administração a tomar decisões, onde coleta todos os dados econômicos, mensurados monetariamente, registrando e sumarizando formas de relatórios ou de comunicados, que contribuem para a tomada de decisões. O autor explica ainda que ela é voltada para fins internos, procurando suprir os gerentes de um elenco maior de informações, exclusivamente para a tomada de decisões. Segundo Corbett:

a contabilidade gerencial deve fazer a conexão entre as ações locais dos gerentes e a lucratividade da empresa, para que estes possam saber que direção tomar. Medindo corretamente o impacto de ações locais no desempenho global, a contabilidade gerencial também serve como o agente motivador, pois premia as pessoas que contribuem significativamente ao objetivo da empresa. A contabilidade gerencial tem como objetivo principal fornecer informações para que os gerentes possam decidir qual o melhor caminho para a empresa. (CORBETT, 1997, p. 22).

A contabilidade gerencial tenta, ao mesmo tempo, ser abrangente e concisa, ajustando-se constantemente para se adaptar às mudanças tecnológicas, mudanças nas necessidades dos gestores e novas abordagens das outras áreas funcionais dos negócios (LOUDERBACK et al., 2000).

Para Iudícibus (1998) todo procedimento, técnica, informação ou relatório contábil 
deve ser feito para que a administração os utilize na tomada de decisões entre alternativas conflitantes, ou na avaliação de desempenho. Já Padoveze explica que a contabilidade gerencial é:

O processo de identificação, mensuração, acumulação, análise, preparação, interpretação e comunicação de informações financeiras utilizadas pela administração para planejamento, avaliação e controle dentro de uma organização e para assegurar e contabilizar o uso apropriado de seus recursos. (PADOVEZE, 2000, p. 27).

Vistas toda a importância e as funções da contabilidade gerencial, a próxima seção abordará assuntos sobre micro e pequenas empresas.

\subsection{MICROS E PEQUENAS EMPRESAS}

Os critérios que classificam o tamanho de uma empresa constituem um importante fator de apoio às micro e pequenas empresas (MPE), permitindo que estabelecimentos dentro dos limites instituídos possam usufruir os benefícios e incentivos previstos nas legislações (SEBRAE, 2004). Essas empresas possuem tratamento jurídico diferenciado para enquadramento de impostos, solicitações de financiamentos e exigências de escriturações.

Segundo o Estatuto nacional da microempresa e da empresa de pequeno porte:

consideram-se microempresas ou empresas de pequeno porte a sociedade empresária, a sociedade simples e o empresário a que se refere o art. $966 \mathrm{da}$ Lei no 10.406, de 10 de janeiro de 2002, devidamente registrados no Registro de Empresas Mercantis ou no Registro Civil de Pessoas Jurídicas, conforme o caso, desde que: I - no caso das microempresas, o empresário, a pessoa jurídica, ou a ela equiparada, aufira, em cada ano-calendário, receita bruta igual ou inferior a $\mathrm{R} \$ 240.000,00$ (duzentos e quarenta mil reais); II - no caso das empresas de pequeno porte, o empresário, a pessoa jurídica, ou a ela equiparada, aufira, em cada ano-calendário, receita bruta superior a $\mathrm{R} \$ 240.000,00$ (duzentos e quarenta mil reais) e igual ou inferior a $\mathrm{R} \$ 2.400 .000,00$ (dois milhões e quatrocentos mil reais). (BRASIL, 2006).

Neste sentido, segundo o SEBRAE (2004), as MPE são um dos principais pilares de sustentação da economia brasileira, quer pela sua enorme capacidade geradora de empregos, quer pelo infindável número de estabelecimentos desconcentrados geograficamente. Em termos percentuais, esse segmento empresarial representa 25\% do Produto Interno Bruto (PIB), gera 14 milhões de empregos, ou seja, 60\% do emprego formal no país, e constitui $99 \%$ dos 6 milhões de estabelecimentos formais existentes, respondendo ainda por 99,8\% das empresas que são criadas a cada ano.

Para Barretto (2011), as MPE são as grandes geradoras de oportunidades de emprego 
e renda, também considerada o motor do nosso mercado interno. Segundo Marion (1982), é importante destacar que devido ao mau gerenciamento nas empresas, principalmente as pequenas, elas têm falido ou enfrentam sérios problemas de sobrevivência.

Para o sucesso de uma empresa, se faz necessária a exigência de um elenco de informações reais, que norteiam as decisões. Neste contexto, segundo Silva (2002, p. 23), uma empresa sem contabilidade é uma entidade sem memória, sem identidade e sem as mínimas condições de sobreviver ou de planejar seu crescimento. Para Longenecker (1997), os administradores precisam ter informações precisas, significativas e oportunas, se quiserem tomar boas decisões. Isso é particularmente verdadeiro quando se refere à necessidade de informações financeiras sobre as operações da empresa.

\section{METODOLOGIA}

Com o intuito de saber como é a realidade dentro das empresas ao que se refere à contabilidade gerencial, para a realização do presente artigo, aplicou-se um questionário aos empresários e gestores de diversos ramos, a fim de se identificar como os mesmos utilizam as ferramentas gerenciais.

A pesquisa foi realizada nos bairros de Curitiba e região metropolitana, nos três setores principais: comércio, indústria e serviços. O questionário foi aplicado em 20 estabelecimentos, visando à identificação do uso das ferramentas gerenciais e qual a importância do profissional contábil dentro da organização.

Através destas, visou-se verificar o papel do contador em suas organizações, questionou-se o uso das ferramentas gerenciais no dia a dia e se estas ferramentas e informações transmitidas pelo contador servem como base para a solução e identificação de problemas dentro da organização. Em relação à forma de aplicação do questionário, 16 foram via e-mail, representando $80 \%$, e 4 diretamente nos locais, representando $20 \%$.

\section{ANÁLISE DOS DADOS}

A análise de dados levou em consideração a importância da contabilidade gerencial nas empresas, incluindo nesta pesquisa elementos que norteiam o uso da contabilidade em MPE. A Tabela 1 evidencia o tipo de contabilidade adotada pelas empresas.

TABELA 1 - TIPO DE CONTABILIDADE

\begin{tabular}{cr|r|r}
\hline Descrição & \multicolumn{1}{c|}{ Indústria } & Comércio & \multicolumn{1}{c}{ Serviços } \\
\hline Contabilidade externa & $100 \%$ & $82 \%$ & $37 \%$ \\
Contabilidade interna & $0 \%$ & $18 \%$ & $63 \%$ \\
\hline
\end{tabular}

FONTE: Elaborado pelos autores (2011). 
O objetivo da questão era saber como a contabilidade das empresas era feita. No ramo do comércio observou-se que $82 \%$ das contabilidades são externas. Já no ramo de prestação de serviços $63 \%$ das contabilidades são executadas internamente. Em relação às indústrias de pequeno e médio porte pesquisadas, todas fazem sua contabilidade externamente. O Gráfico 1 evidencia a utilização gerencial do contador por parte dos empresários.

\section{GRÁFICO 1 - VISÃO GERENCIAL DO CONTADOR}

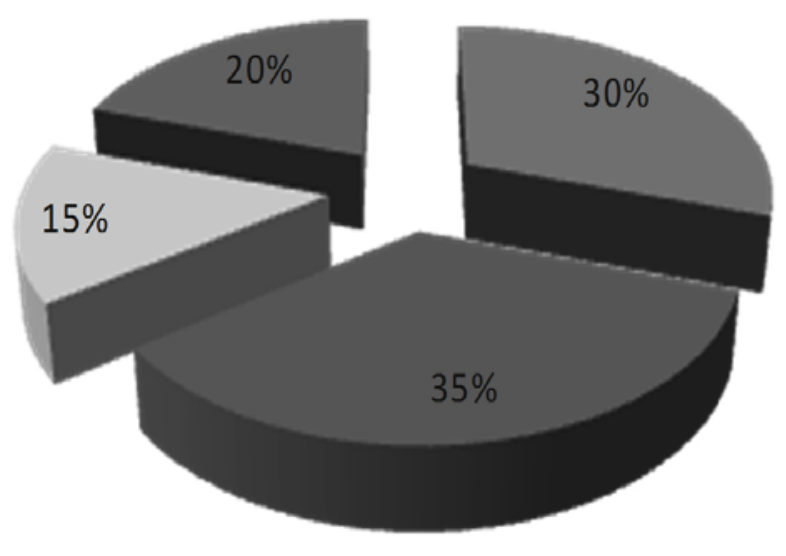

\section{- $30 \%$ Auxiliador nas tomadas de decisões \\ - $35 \%$ Aquele que propõe medidas corretivas a fim de melhorar a eficiência da empresa \\ 15\% Apenas um informante de dados}

\section{- $20 \%$ Não utiliza essas funções do contador}

FONTE: Elaborado pelos autores (2011).

Nesta questão, o objetivo foi obter a opinião dos gestores sobre seu contador. Pode-se observar que $35 \%$ dos empresários vêem o contador como aquele que propõe medidas corretivas a fim de melhorar a eficiência da empresa, 30\% como auxiliador nas tomadas de decisões, $15 \%$ apenas como um informante de dados e $20 \%$ não utilizam essas funções do contador. Este papel do contador, de auxílio na tomada de decisões dentro das organizações, sempre com o intuito de contribuir para o sucesso empresarial, é muito importante. O Gráfico 2 apresenta as respostas acerca do uso das ferramentas gerenciais.

GRÁFICO 2 - USO DE FERRAMENTAS GERENCIAIS
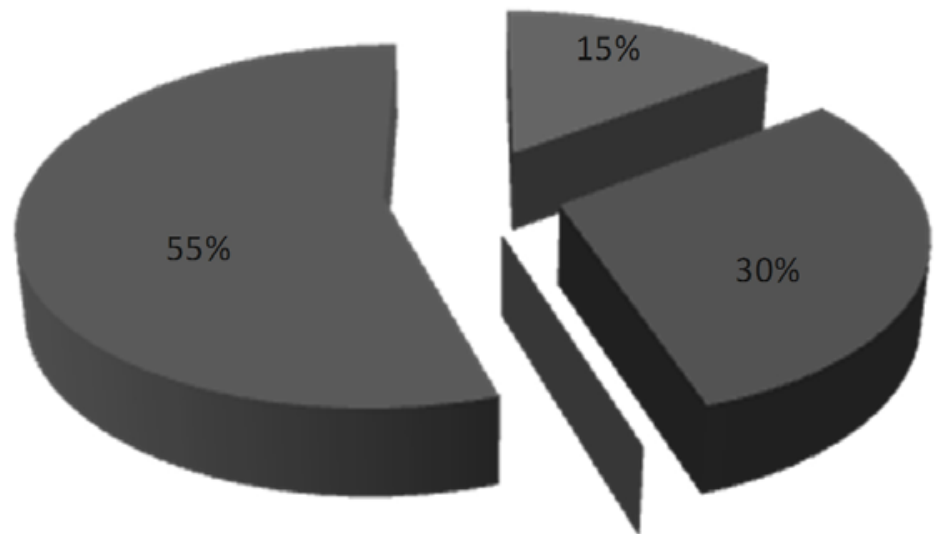

- 15\% Orçamento em presarial

- $30 \%$ Fluxo de caixa

- $\%$ Análise da margem de contribuição

- 55\% Todas as opções

FONTE: Elaborado pelos autores (2011). 
Questionou-se, neste item, sobre as ferramentas gerenciais utilizadas nas organizações. Observou-se que 15\% utilizam a ferramenta de orçamento empresarial, 30\% de fluxo de caixa, que a análise da margem de contribuição não é utilizada sozinha e que 55\% utilizam todas as ferramentas. Visto que estas ferramentas são criadas para ajudar e possibilitar uma administração mais clara e focada, se descartadas ou pouco conhecidas, podem comprometer o futuro da organização. O Gráfico 3 ilustra a frequência de contato entre a empresa e o seu contador.

\section{GRÁFICO 3 - FREQUÊNCIA DE CONTATO: ORGANIZAÇÃO E CONTADOR}

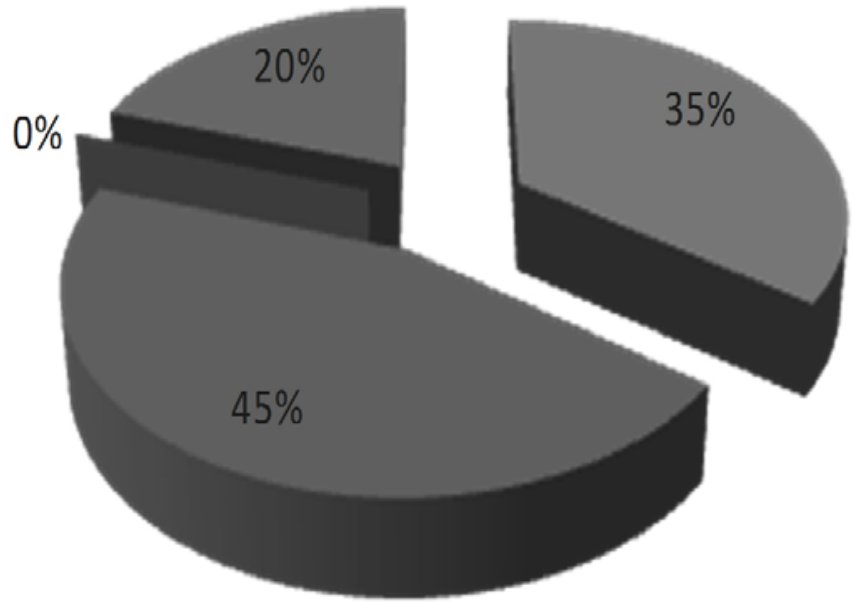

- $35 \%$ Diariamente

- $45 \%$ Mensalmente

$0 \%$ Anualmente

- 20\% Quando necessário

FONTE: Elaborado pelos autores (2011).

Quanto à frequência de contato entre organização e contador, a intenção da questão foi destacar qual a periodicidade da relação entre estes. Conforme o Gráfico 3, percebe-se que $35 \%$ possuem contato diário, $45 \%$ mensal e $20 \%$ somente quando necessário. Nenhuma empresa solicita informações apenas anualmente. O Gráfico 4 mostra o período de análise das informações obtidas por meio de balanços.

GRÁFICO 4 - PERIODICIDADE DE ANÁLISE DOS RESULTADOS

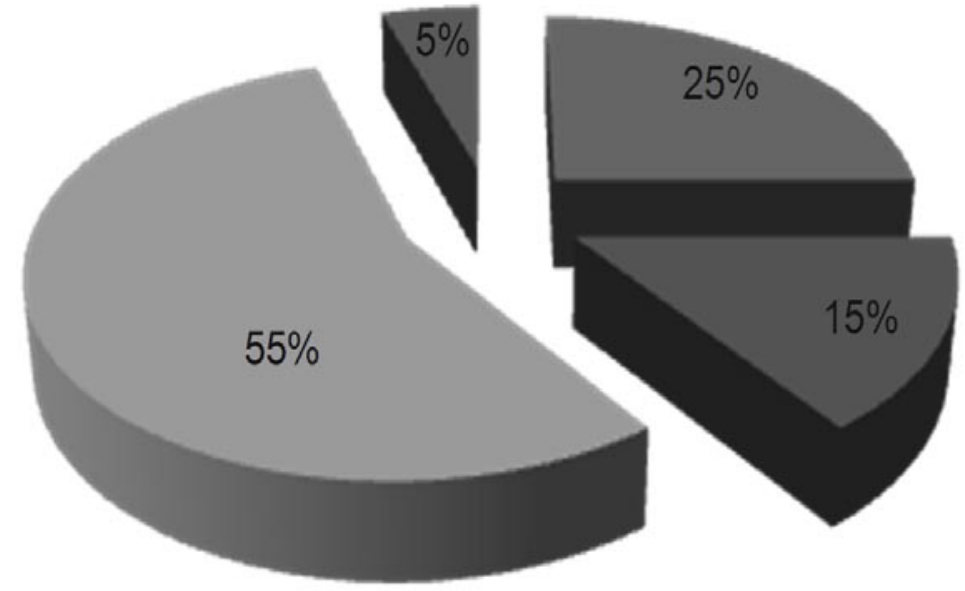

- $25 \%$ Trimestral

- $15 \%$ Semestral

$55 \%$ Anual

- $5 \%$ Outros

FONTE: Elaborado pelos autores (2011). 
Nesta questão, o objetivo foi verificar com que frequência a empresa costuma solicitar suas informações econômicas e financeiras, juntamente com as demonstrações contábeis, uma vez que essas análises possuem importante papel gerencial. Verificou-se que $25 \%$ solicitam as informações trimestralmente, $15 \%$ semestralmente, $55 \%$ anualmente e $5 \%$ em outros períodos de tempo. Segundo Matarazzo (1995), analisar o balanço é uma necessidade para um grande número de pessoas: internos (administradores) e externos (fornecedores, bancos). A Tabela 2 apresenta duas questões do tipo binárias apresentadas nos questionários.

TABELA 2 - QUESTÕES BINÁRIAS ADICIONAIS

\begin{tabular}{|c|c|c|}
\hline Questão & Sim & Não \\
\hline $\begin{array}{l}\text { Além das guias para pagamento dos impostos, seu contador lhe fornece os resultados da sua } \\
\text { empresa? }\end{array}$ & $50 \%$ & $50 \%$ \\
\hline $\begin{array}{l}\text { As informações transmitidas por parte do contador são admitidas para corrigir problemas } \\
\text { gerenciais da organização? }\end{array}$ & $60 \%$ & $40 \%$ \\
\hline
\end{tabular}
FONTE: Elaborado pelos autores.

Analisando as informações obtidas nestas duas questões, é possível visualizar que 50\% dos contadores fornecem além das guias de pagamentos, relatórios com os resultados obtidos no período. Com esses resultados $60 \%$ dos administradores aceitam favoravelmente as sugestões dos contadores, com o intuito de corrigir alguns pontos que podem ser os responsáveis pelos resultados negativos daquele período.

\section{CONSIDERAÇÕES FINAIS}

O objetivo desta pesquisa era analisar a contabilidade gerencial dentro do contexto das MPE. O uso da contabilidade gerencial está em seu estágio inicial nestas empresas, e ainda possui um imenso mercado para crescimento nestes tipos de entidades. Ela vem auxiliando empresários administradores nas tomadas de decisões e se tornando uma ferramenta fundamental dentro das MPE, assim como já é nas empresas de grande porte.

Observou-se que grande parte das entidades ainda usam escritórios contábeis externos para fazer suas contabilidades. A visão que os empresários possuem de seus contadores vêm melhorando ao longo do tempo, principalmente em função de grandes mudanças contábeis, proposta pela Lei 11.638/07. Apesar disto, verificou-se que 35\% dos entrevistados pouco utilizam seu contador, no contexto gerencial.

Os $45 \%$ de respondentes que afirmaram que a frequência de contato empresa-contabilidade é mensal confirmam o fato de que o contador ainda é visto apenas como um "fornecedor de guias de pagamentos”, apesar de que esta visão está mudando para melhor. Esta informação corrobora com as questões binárias adicionais apresentadas. Neste sentido, para buscar 
melhores conclusões acerca do tema, sugere-se, para próximas pesquisas nas MPE, aumentar o número da amostra pesquisada.

\section{REFERÊNCIAS}

ARRUDA, M. A inserção de produtos no mercado. Revista Sebrae, Brasília, n. 6, p. 69-73, set./out. 2002

ATKINSON, A. A. et al. Contabilidade gerencial. Tradução de: CASTRO, A. O. M. C. 2. ed. São Paulo: Atlas, 2000.

BARRETO, G. Análise bibliográfica sobre a contabilidade gerencial. 67 p. Monografia (Graduação em Ciências Contábeis) - Faculdades Integradas Antônio Eufrásio de Toledo, Presidente Prudente, 2011.

BRASIL. Casa Civil. Lei complementar n. 123, de 14 de dezembro de 2006. Estatuto nacional da microempresa e da empresa de pequeno porte. Brasília, 14 dez. 2006. Disponível em: <http://www.receita.fazenda.gov.br/legislacao/leiscomplementares/2006/leicp123.htm>.

CORBETT NETO, T. Contabilidade de ganhos: a nova contabilidade gerencial de acordo com a teoria das restrições. São Paulo: Nobel, 1997.

CRITÉRIOS e conceitos para classificação de empresas. Disponível em: < http:/ www.sebrae. com.br/momento/quero-abrir-um-negocio/integra_bia?ident_unico $=97>$.

HANSEN, D. R.; MOWEN, M. M. Cost management. 2. ed. Cincinnati: South-Western College Publications, 1997.

IUDÍCIBUS, S. de. Contabilidade gerencial. 6. ed. São Paulo: Atlas, 1998.

LACERDA, J. B. A contabilidade como ferramenta gerencial na gestão financeira das micro, pequenas e médias empresas (MPMEs): necessidade e aplicabilidade. Disponível em: <http:// www.biblioteca.sebrae.com.br/bds/BDS.nsf/4D0B9C74BD56C03803257053005D83A8/ \$File/NT000AA6DE.pdf>.

LONGENECKER, J. G.; MOORE, C. W.; PETTY, J. W. Administração de pequenas empresas. São Paulo: Makron Books, 1997.

LOUDERBACK, J. G.; HOLMEN, J.; DOMINIAK, G. Managerial accounting. 9. ed. Cincinnati: South-Western College Publications, 2000.

MARION, J. C. Contabilidade empresarial. São Paulo: Atlas, 1982.

MATARAZZO, D. C. Análise financeira de balanço: abordagem básica e gerencial. 3. ed. São Paulo: Atlas, 1995.

PADOVEZE, C. L. Contabilidade gerencial - Um enfoque em sistema de informação contábil. 3. ed. São Paulo: Atlas, 2000.

SEBRAE. Revista Conhecer, n. 17, 2011.

SILVA, D. S. Manual de procedimentos contábeis para micro e pequenas empresas. 5. ed. Brasília: CFC: Sebrae, 2002.

ZANLUCA, J. C. Planejamento tributário - todos nós precisamos dele. Disponível em: $<$ http://www.portaltributario.com.br/>. Acesso em: 10/2011. 